Check for updates

Cite this: RSC Adv., 2019, 9, 28478

\title{
Confluence of montmorillonite and Rhizobium towards the adsorption of chromium(vi) from aqueous medium
}

\author{
T. Sathvika, ${ }^{a}$ Akhil Raj Kumar Saraswathi, ${ }^{a}$ Vidya Rajesh ${ }^{b}$ and N. Rajesh (DD *a
}

Chromium in its hexavalent oxidation state is carcinogenic and wastewater from the electroplating industry is one of the principal sources of pollution. To reduce this toxicity and pave way towards environmental safety, a combination of environmental microbiology and chemistry is quite efficient for developing biosorbents to sequester chromium from waste water. Immobilization of Rhizobium in sodium montmorillonite provides a conducive environment to capture hexavalent chromium. Various characterization techniques such as FTIR, XPS and SEM-EDAX were performed and batch parameters such as $\mathrm{pH}$ variation, adsorbent dosage, concentration of metal ion and temperature were optimized. Pseudo second order kinetics coupled with a higher regression coefficient for Freundlich isotherm and a Langmuir adsorption capacity of $22.22 \mathrm{mg} \mathrm{g}^{-1}$ was achieved for the adsorption process. The adsorption was enhanced by the charge interactions between the protonated clay-Rhizobium surface and $\mathrm{Cr}(\mathrm{VI})$ ions in acidic medium. The biosorbent was stable and easily regenerated using $\mathrm{NaOH}$. Preliminary column studies were performed to test the efficiency of the developed biosorbent at higher volumes on a laboratory scale.

Received 18th July 2019

Accepted 15th August 2019

DOI: $10.1039 /$ c9ra05528b

rsc.li/rsc-advances

of reagents and greater energy consumption. ${ }^{5}$ In order to combat most of these disadvantages, biosorption has proven to be a viable choice for the removal and recovery of heavy metals.

The surface adsorption process which involves the use of active or inactive microbes is termed as biosorption. When the active microbes are involved in adsorption it is termed to be active mechanism and is a metabolism dependent process, wherein use of inactive microbes is metabolism independent passive mechanism. ${ }^{6}$ There are also some drawbacks with the direct use of primitive microbes such as poor mechanical strength, regeneration ability and microbial separation from solvent. ${ }^{7}$ Hence immobilization of microbes in suitable matrices helps in gaining porosity, rigidity, mechanical strength, low sludge formation, easy handling and good regeneration ability. ${ }^{8}$ The functional groups present in the microbial cell walls aid in complexing the heavy metals. ${ }^{9}$ The bio based and eco-friendly materials are used for many applications. Recent literature highlights the importance of bio based materials and eco-friendly sorbents. The utility of molecularly imprinted biopolymers based on a green synthesis strategy for determination of B-family vitamins $^{10}$ and for clean separation of baclofen from bio-fluid samples has been reported. ${ }^{11}$ Molecularly imprinted nanoparticles based on functionalized silica as an efficient sorbent for the determination of acrylamide in potato chips and a green synthetic route for water-compatible molecularly imprinted nanoparticles for the extraction of hydrochlorothiazide from human urine has been reported recently. 12,13

The removal of $\mathrm{Cr}(\mathrm{vI})$ by few of the recently reported biosorbents include Saccharomyces cerevisiae immobilized in crosslinked 
cellulose using microwave radiation has an adsorption capacity of $23.61 \mathrm{mg} \mathrm{g}^{-1} \cdot{ }^{14}$ The immobilization of Rhizobium and yeast in functionalized carbon nanotubes have Langmuir adsorption capacities of $24.86 \mathrm{mg} \mathrm{g}^{-1}$ and $31.6 \mathrm{mg} \mathrm{g}^{-1}$ for $\mathrm{Cr}(\mathrm{vI})$ removal. ${ }^{15}$ Aspergillus BVR immobilized in sodium montmorillonite ${ }^{16}$ and cellulose $^{17}$ also showed good efficacy in adsorbing $\mathrm{Cr}(\mathrm{vI})$. Adsorption coupled reduction of $\mathrm{Cr}(\mathrm{vI})$ has been observed as the mechanism involving the inactive biomass of Aspergillus niger. ${ }^{18}$

The nitrogen fixing bacteria Rhizobium is a Gram negative, rod shaped prokaryote which provides nutrients to the plants by increasing the agronomic output and also helps in regulating fungal root infections. ${ }^{19,20}$ The carbon and nitrogen sources available in the sludge generated from the agro based industries offers an economic route for growth of Rhizobium and also a sustainable alternative in wastewater treatment. ${ }^{21} \mathrm{Cr}$ (III) at $\mathrm{pH} 7.0$ was removed using the activated biomass of Rhizobium leguminosarum with an efficiency of $84.4 \pm 3.6 \%{ }^{22}$ Clays possess hydrous aluminosilicate tetrahedral and octahedral layers with cation exchange properties and has several advantages such as large surface area, ordered structure, intercalation and good thermal and chemical stabilities. ${ }^{23}$ Montmorillonite is a 2:1 type of clay with an aluminum tetrahedron sheet sandwiched between two silica octahedral sheets with exchangeable cations which counteract the negative charge produced in the isomorphic substitution. ${ }^{24}$ There are several reports on adsorption of Cr(vi) using clays such as montmorillonite supported magnetite nanoparticles that could adsorb up to $15.3 \mathrm{mg} \mathrm{g}^{-1} \mathrm{Cr}(\mathrm{vI})$. Clay-biopolymer composites such as cellulose-clay $^{25}$ also has good potential for $\mathrm{Cr}(\mathrm{vI})$ removal. The reduction of $\mathrm{Cr}(\mathrm{vI})$ has been correlated to the content of $\mathrm{Fe}^{2+}$ ions present in dithionite reduced smectite. ${ }^{26}$

As the microbe-clay combination can exist in similar ecological environment it could remove several organic pollutants. ${ }^{27}$ Hence the combination of inactive or dead microbes in conjunction with clays would be advantageous to sequester hexavalent chromium. There are relatively few reports for heavy metal sequestration using microbial-clay combination. The current study demonstrates and highlights the importance of microbe modified sodium montmorillonite for $\mathrm{Cr}(\mathrm{vI})$ removal wherein the isolated Rhizobium species was immobilized in clay using ultrasonication. The developed clay-Rhizobium biosorbent was subjected to comprehensive characterization and batch studies were conducted to adsorb $\mathrm{Cr}(\mathrm{vI})$ from aqueous medium.

\section{Materials and methods}

\subsection{Chemicals and materials}

Analytical and guaranteed grade reagents were used throughout the experiments. A $1000 \mathrm{mg} \mathrm{L^{-1 }} \mathrm{Cr}(\mathrm{vI})$ stock solution was prepared using $\mathrm{K}_{2} \mathrm{Cr}_{2} \mathrm{O}_{7}$ (Merck) and various working concentrations were prepared by further dilution. Ultrapure (Millipore) water was used to prepare aqueous solutions. Montmorillonite, K-10 was purchased from Sigma Aldrich. The chemicals used in the YMA (Yeast extract, Mannitol) media for microbial culture were procured from Himedia, India.

An ultra-sonication bath (Biotechnics, India) was used for the immobilization of Rhizobium BVR in montmorillonite. Various analytical techniques were used to characterize the developed biosorbent. FTIR spectrum was recorded using JASCO-4200 model FTIR spectrometer by mixing $100 \mathrm{mg}$ of $\mathrm{KBr}$ with $1 \mathrm{mg}$ of the biosorbent. A S3400N model Scanning electron microscope (Hitachi) which was associated with Thermo Electron EDAX system was used to understand the morphology of the biosorbent. A post derivatized technique for the estimation of $\mathrm{Cr}(\mathrm{vI})$ at $540 \mathrm{~nm}$ after the adsorption was performed using 883 Basic IC plus Ion chromatography with UV-Visible detector. Leica DMi8 laser scanning confocal microscopy (S/N 418513) with a TCS SP8 scanner was used to obtain the confocal images. A Jasco V650 UV visible spectrophotometer was used to determine the concentration of chromium(vi) during the column studies. The survey scan spectra was recorded using XPS PHI 5000 Versa Prob II, FEI Inc, using aluminum monochromator of power $25.4 \mathrm{~W}$ and $187.8 \mathrm{eV}$.

\subsection{Preparation of the clay-Rhizobium biosorbent}

The sodium form of montmorillonite (NaMMT) was prepared by treating montmorillonite with sodium chloride as described in literature. ${ }^{28}$ The isolated Rhizobium BVR was grown in YMA broth medium and complete characterization of the microbe has been reported in our earlier studies ${ }^{\mathbf{1 5}}$ and assigned an accession number MF136764 by NCBI genbank. The grown culture was centrifuged to obtain a pellet. A $2.0 \mathrm{~g}$ weight of Rhizobium was mixed with $1.0 \mathrm{~g}$ of NaMMT in aqueous medium and subjected to sonication for about $8 \mathrm{~min}(50 \mathrm{~W}, 230 \mathrm{~V})$ to ensure the bacterial surface immobilization in sodium montmorillonite. The NaMMT-Rhizobium biosorbent was filtered, rinsed with water and dried for further experimental studies. The biosorbent developed is pale yellow in color and has varied functional groups which could adsorb $\mathrm{Cr}(\mathrm{vI})$.

\subsection{Synthesis of probes for $\mathrm{Cr}(\mathrm{VI})$ and $\mathrm{Cr}(\mathrm{III})$}

$\mathrm{Cr}(\mathrm{VI})$ and $\mathrm{Cr}(\mathrm{III})$ were also differentiated by specific binding probes such as Rhodamine sensors where the spirolactam structure and spiro ring opening mechanism play a key role. The synthesis of Cr species specific probes, Rhodamine B hydrazide $(\mathrm{RBH})^{29}$ and Rhodamine based chemosensor $(\mathrm{RF})^{\mathbf{3 0}}$ was done as described previously. The probes synthesized were mixed with the samples for capturing the laser confocal microscopy images.

\subsection{Biosorption studies}

The biosorption experiments were optimized by conducting batch studies using $0.2 \mathrm{~g}$ of the prepared NaMMT-Rhizobium biosorbent in $30 \mathrm{~mL}$ of $5 \mathrm{mg} \mathrm{L}{ }^{-1}$ working $\mathrm{Cr}(\mathrm{vI})$ solution. The temperature variations at different time intervals with an agitation speed of $120 \mathrm{rpm}$ was performed in an incubator shaker (Biotechnics, India). The $\mathrm{Cr}(\mathrm{vI})$ concentration left in solution was quantitatively analyzed using ion chromatography technique through post column derivatization using diphenyl carbazide. ${ }^{31}$ The adsorption capacity of the biosorbent containing $\mathrm{Cr}(\mathrm{vI})(\mathrm{mg}$ $\left.\mathrm{g}^{-1}\right)$ after reaching equilibrium $\left(q_{\mathrm{e}}\right)$ was calculated using

$$
q_{\mathrm{e}}=\frac{\left(C_{\mathrm{o}}-C_{\mathrm{e}}\right) V}{W}
$$

where $q_{\mathrm{e}}=\mathrm{Cr}(\mathrm{vI})\left(\mathrm{mg} \mathrm{g}^{-1}\right)$ after adsorption onto biosorbent, $C_{\mathrm{o}}$ $=$ initial $\mathrm{Cr}(\mathrm{vI})$ concentration $\left(\mathrm{mg} \mathrm{L}^{-1}\right), C_{\mathrm{e}}=\mathrm{Cr}(\mathrm{vI})$ concentration 

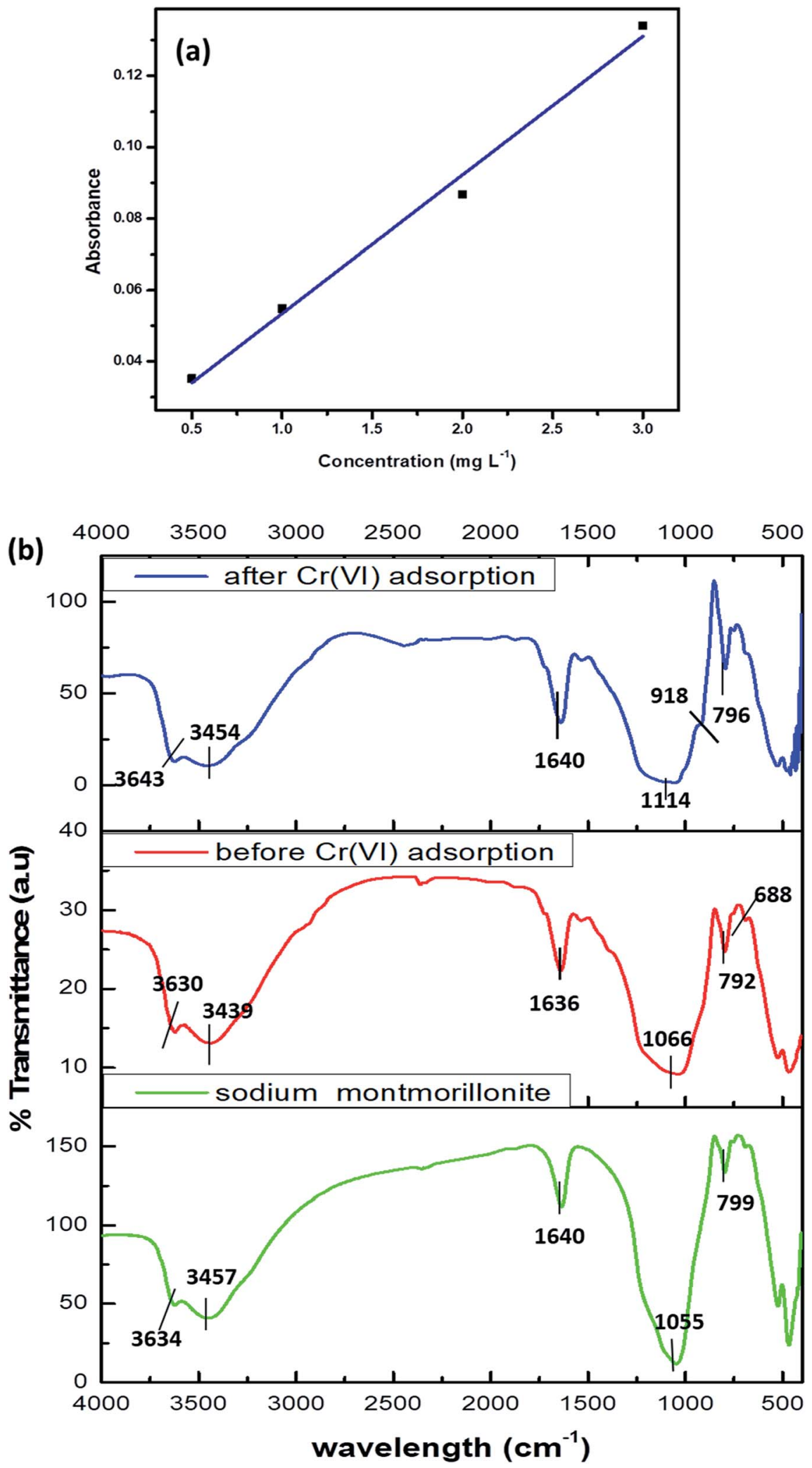

Fig. 1 (a) Calibration graph of $\mathrm{Cr}(\mathrm{VI})$ (b) FTIR of sodium montmorillonite, biosorbent before and after $\mathrm{Cr}(\mathrm{VI})$ adsorption. 
at equilibrium $\left(\mathrm{mg} \mathrm{L}^{-1}\right) V=$ volume of $\mathrm{Cr}(\mathrm{vI})$ solution (L) and $W$ $=$ weight of clay-Rhizobium biosorbent $(\mathrm{g})$.

The calibration graph of $\mathrm{Cr}(\mathrm{VI})$ was performed in the range 0$3 \mathrm{mg} \mathrm{L}{ }^{-1}$ and is presented in Fig. $1 \mathrm{a}$.

\section{Results and discussion}

\subsection{Characterization of the clay-Rhizobium biosorbent}

The frequency shifts in the IR spectrum reveals the participation of hydroxyl, amino, carboxyl functional groups present in the microbial cell walls. The characteristic band for clays was observed at $3643 \mathrm{~cm}^{-1}$ corresponding to the $\mathrm{Si}-\mathrm{OH}$ functional groups. ${ }^{16,32}$ The hydroxyl and amine functional groups and also the Al-O-H stretching vibrations together contribute to the broad band at $3454 \mathrm{~cm}^{-1}$. The $\mathrm{Si}-\mathrm{O}-\mathrm{Si}$ stretching of clay was observed at $1114 \mathrm{~cm}^{-1}$ and the amide-I band at $1640 \mathrm{~cm}^{-1}$ (ref. 32) could be attributed to the bacteria and hydrogen bonding in water. The other characteristic peaks for montmorillonite at $792 \mathrm{~cm}^{-1}$ and $688 \mathrm{~cm}^{-1}$ indicates the broadening of quartz and silica and $\mathrm{Si}-\mathrm{O}$ bond deformation respectively. ${ }^{25} \mathrm{~A}$ shouldering peak at $918 \mathrm{~cm}^{-1}$ corresponding to $\mathrm{Cr}=\mathrm{O}$ after adsorption of hexavalent chromium ${ }^{\mathbf{1 6}}$ is an evidence for metal adsorption as shown in Fig. 1b.

The morphological features of the Rhizobium immobilized in clay captured using SEM showed assorted clusters (Fig. 2) and also the elemental analysis through EDAX showed the presence of elements such as $\mathrm{Na}, \mathrm{K}, \mathrm{Al}, \mathrm{Si}$ respectively. The presence of $\mathrm{Cr}$ peak between 5-6 keV after adsorption confirmed $\mathrm{Cr}(\mathrm{vI})$ adsorption (Fig. 2). The possible reduction of $\mathrm{Cr}(\mathrm{vI})$ was explored using X-ray photo electron spectroscopy since microbial adsorption mechanism is often coupled with reduction. The survey scan revealed the presence of elements such as $\mathrm{C}$, $\mathrm{O}, \mathrm{N}, \mathrm{Cr}$ (Fig. 3a) and the short scan of the $\mathrm{C}$ 1s peak was corrected to $284.8 \mathrm{eV}$ (Fig. 3b). The binding energies in the survey scan showed a peak at $576.9 \mathrm{eV}$ that corresponds to $\mathrm{Cr}$ (III) and $585.7 \mathrm{eV}$ which is characteristic of $\mathrm{Cr}(\mathrm{vI}) .{ }^{33}$ It was observed that there was no immediate reduction after biosorption of $\mathrm{Cr}(\mathrm{VI})$ and the clay-Rhizobium surface turned pale green only after few days signifying the formation of $\mathrm{Cr}$ (III).

Specific rhodamine based sensors were utilized in the characterization to differentiate $\mathrm{Cr}(\mathrm{III})$ and $\mathrm{Cr}(\mathrm{VI})$ with laser confocal microscopy by using probes such as RBH and RF as discussed in our earlier work..$^{15,29,30}$ The bright field and fluorescent images are shown in Fig. $4 \mathrm{a}-\mathrm{h}$. The images captured before and after addition of probes confirmed the presence of $\mathrm{Cr}(\mathrm{VI})$ and $\mathrm{Cr}(\mathrm{III})$ respectively. The pink color formation indicates the presence of chromium in their respective oxidation states using the above probes.

\subsection{Effect of $\mathbf{p H}$, adsorbent dosage and interaction mechanism for biosorption}

In accordance with the $\mathrm{pH}$ of the aqueous phase, hexavalent chromium is present as hydrogen chromate $\left(\mathrm{HCrO}_{4}{ }^{-}\right)$,
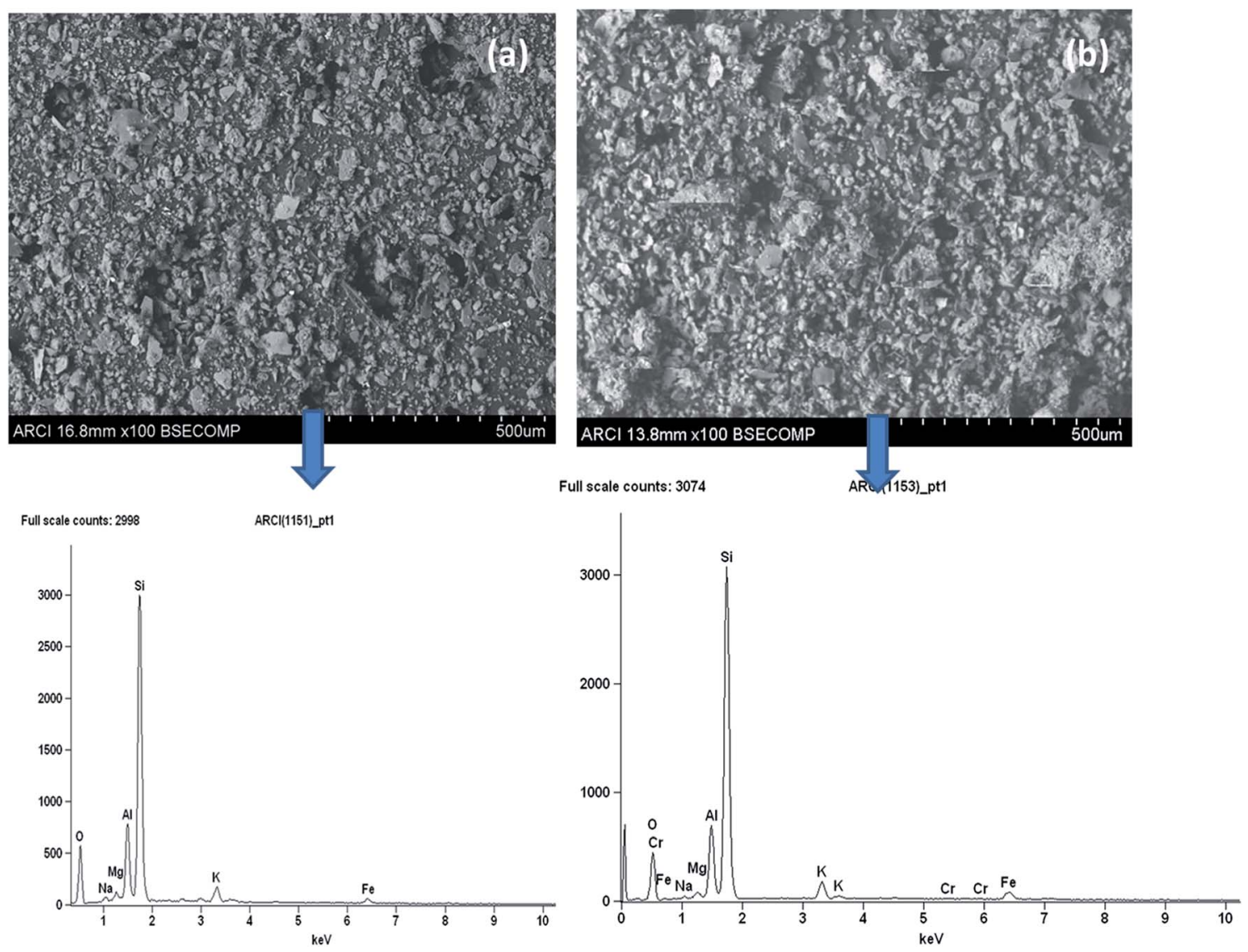

Fig. 2 SEM and EDAX images of the biosorbent (a) before $\mathrm{Cr}(\mathrm{vl})$ adsorption (b) after $\mathrm{Cr}(\mathrm{VI})$ adsorption. 

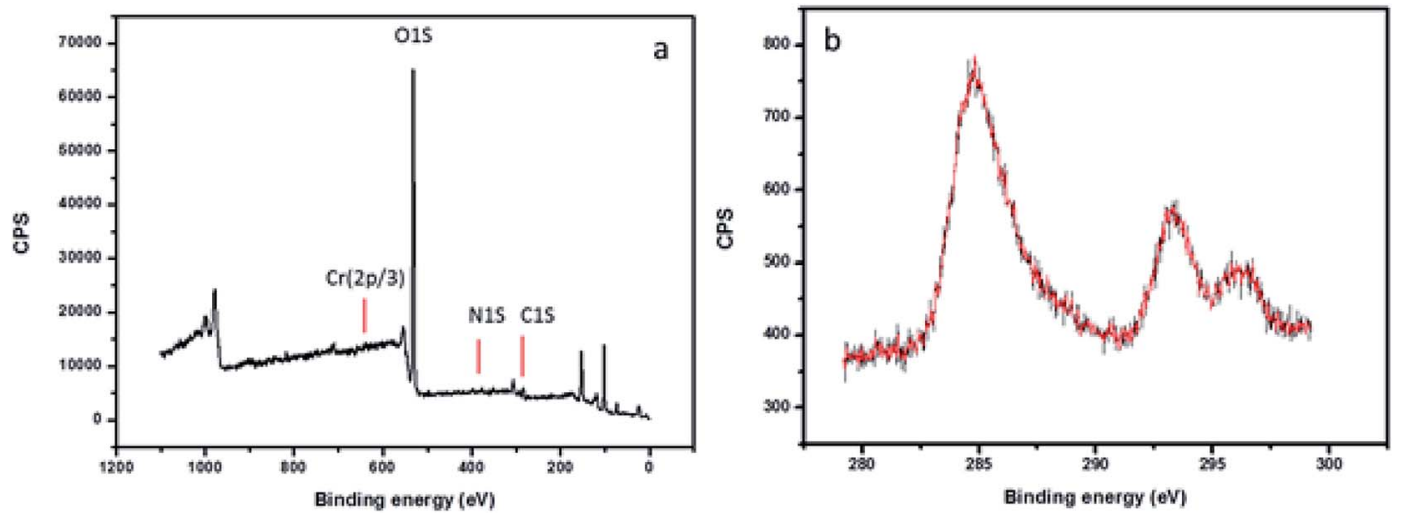

Fig. 3 XPS spectra of the biosorbent after $\mathrm{Cr}(\mathrm{VI})$ adsorption (a) survey scan spectra (b) high resolution spectra of $\mathrm{C} 1 \mathrm{~s}$.

dichromate $\left(\mathrm{Cr}_{2} \mathrm{O}_{7}{ }^{2-}\right)$ and chromate $\left(\mathrm{CrO}_{4}{ }^{2-}\right)$ oxy anions respectively. The dichromate and hydrogen chromate anions exist in equilibrium and the plausible mechanism indicates the existence of $\mathrm{HCrO}_{4}{ }^{-}$at $\mathrm{pH}$ greater than or equal to $2.0 .^{34}$ Quantitative adsorption was observed on the surface of the biosorbent at pH 2.0 for a $30 \mathrm{~mL}$ volume of $5 \mathrm{mg} \mathrm{L}^{-1}$ hexavalent chromium concentration (Fig. 5a). The functional groups such as amine, carboxyl, hydroxyl (from microbial surface), silanol and aluminol groups (from clay) are protonated at $\mathrm{pH} 2.0$ resulting in electrostatic interactions with hydro chromate ions. ${ }^{16,25}$ According to hard-soft acid base concept, $\mathrm{Cr}(\mathrm{vI})$ in the form of hydrochromate anion reacts with protonated nitrogen and oxygenated functional groups of the biosorbent resulting in electrostatic interactions. ${ }^{25} \mathrm{At} \mathrm{pH} 2.0$ and at a adsorbent dosage of $0.2 \mathrm{~g}, 30 \mathrm{~mL}$ of $5 \mathrm{mg} \mathrm{L}^{-1} \mathrm{Cr}(\mathrm{vI})$ was adsorbed completely beyond which saturation of active binding sites was observed (Fig. 5b). With increase in $\mathrm{pH}$, decline in adsorption was observed due to the deprotonation of functional groups present on the surface of clay-Rhizobium biosorbent.

\subsection{Equilibrium adsorption isotherms, kinetics and thermodynamic studies}

The association between the adsorbent and the adsorbate at equilibrium was studied using isotherms..$^{35}$ The data obtained (Table 1) is very useful in understanding the mechanism and was fitted with classical isotherms. ${ }^{36}$ The data obtained (Fig. 6ad) depicts the increase in adsorption at higher $\mathrm{Cr}(\mathrm{vI})$ concentrations gradually leading to saturation. The Langmuir model assumes monolayer sorption in which metal ion adsorption occurs on a homogenized surface and there is no contact between the adsorbed ions. The multilayer adsorption which occurs on a heterogeneous surface is described by Freundlich model. Among the two models, Freundlich isotherm, with $r^{2}$
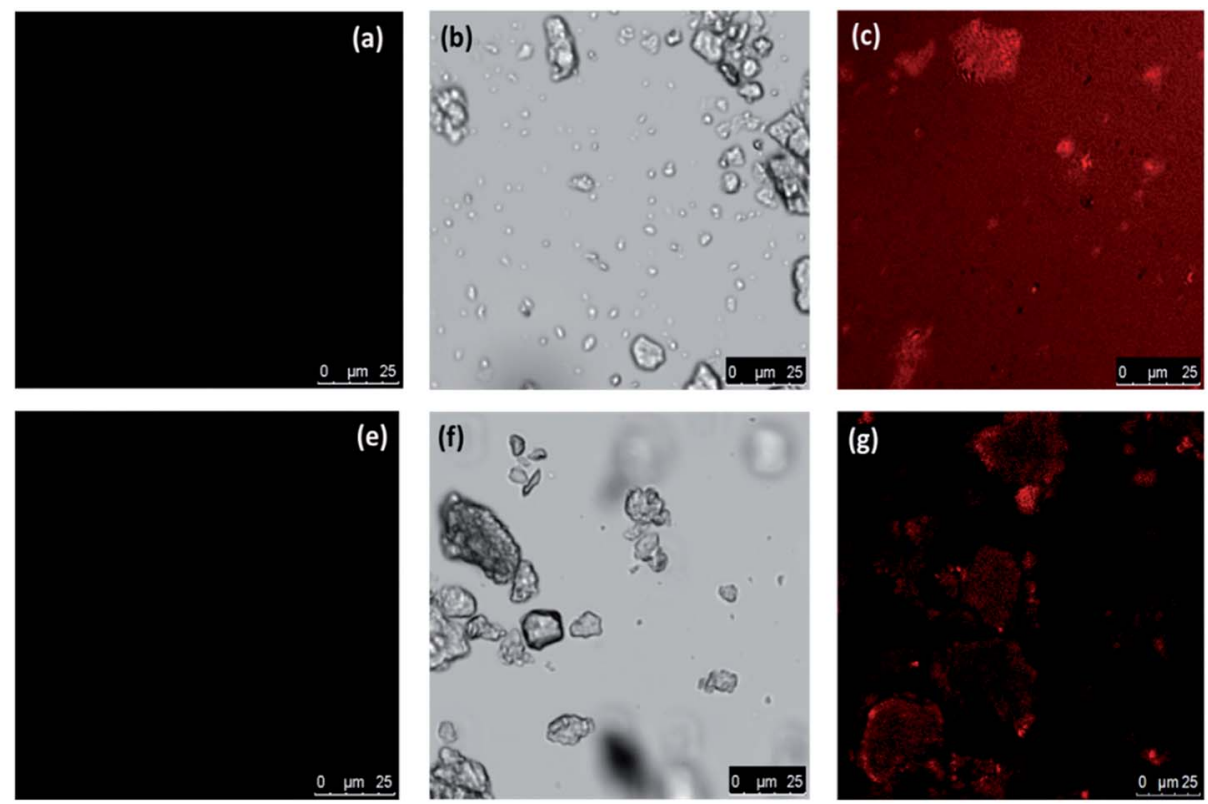
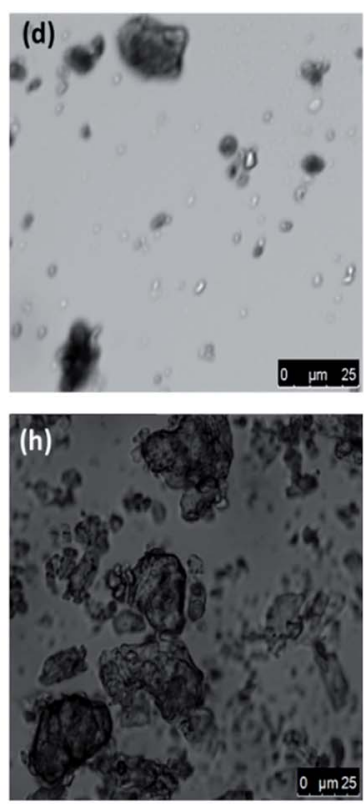

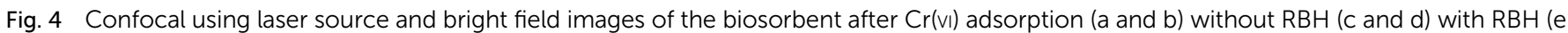
and f) without RF ( $g$ and $h$ ) with RF. 

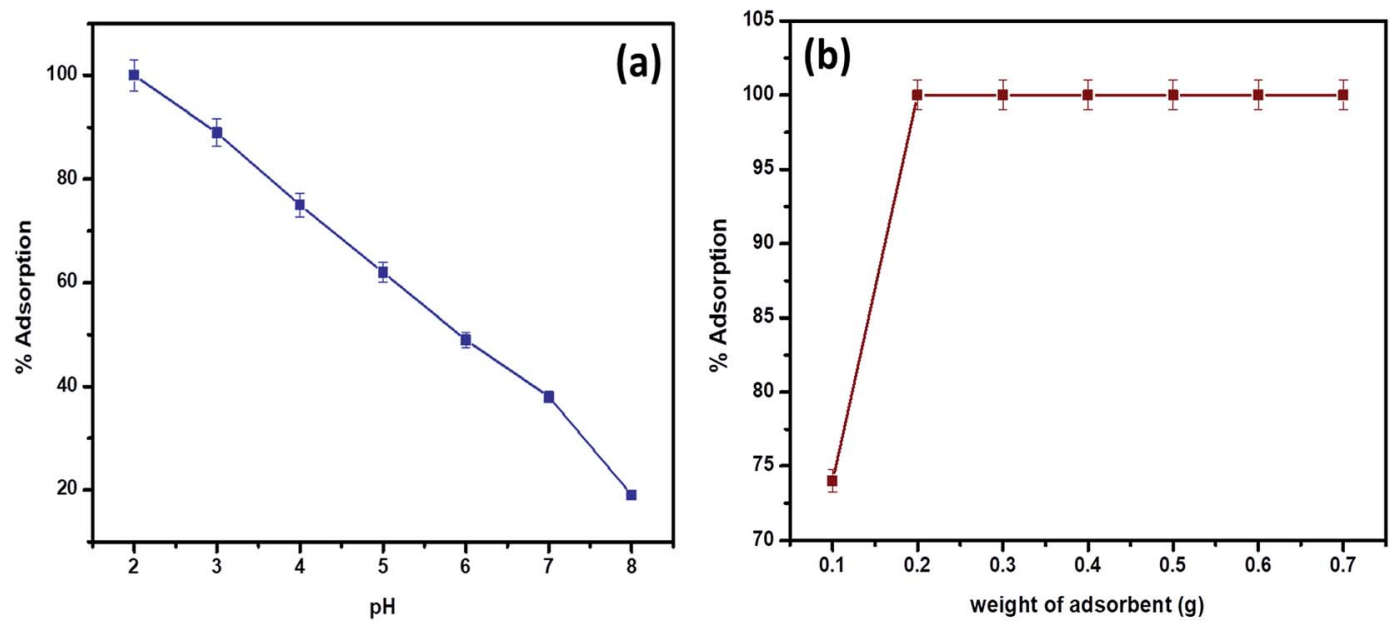

Fig. 5 (a) $\mathrm{pH}$ effect on biosorption (at $30{ }^{\circ} \mathrm{C}, 5 \mathrm{mg} \mathrm{L}^{-1} \mathrm{Cr}(\mathrm{vl})$ ) (b) variation of adsorbent dosage (at $\mathrm{pH} 2.0,30{ }^{\circ} \mathrm{C}, 5 \mathrm{mg} \mathrm{L}{ }^{-1} \mathrm{Cr}(\mathrm{vI})$ ).

value of 0.99 and a low $\chi^{2}$ value of 0.03 was quite appropriate in describing the adsorption process. The favorability of adsorption is also indicated by the value of the exponent in which lies in range of 1-10. The Langmuir adsorption capacity of the system was found to be $22.22 \mathrm{mg} \mathrm{g}^{-1}$ with 0.93 as correlation coefficient and $R_{\mathrm{L}}$ (a dimensionless parameter) given as $R_{\mathrm{L}}=1 / 1$ $+b C_{\mathrm{o}},{ }^{37}$ was below unity and this confirmed the suitability and reversibility of adsorption. Rhizobium BVR strain as such could adsorb $\mathrm{Cr}(\mathrm{vI})$ with an adsorption capacity of $11.5 \mathrm{mg} \mathrm{g}^{-1}$. In addition, Temkin and Dubinin Radushkevich (D-R) isotherms were also studied through the respective plots (Fig. 6) and the corresponding parameters are given in Table 1. Temkin isotherm assumes that there is a linear decrease in the enthalpy of adsorption with incremental surface coverage by the adsorbate. The mean energy obtained from the D-R isotherm which is less than $8 \mathrm{~kJ} \mathrm{~mol}^{-1}$ indicates that the physical adsorption process involves the electrostatic interaction between the functional groups on the Rhizobium-clay surface and hexavalent chromium. The low $r^{2}$ values obtained with Temkin and D-R isotherms indicates that the adsorption mechanism could only be best described through Langmuir and Freundlich isotherms. The maximum adsorption capacities of various related adsorbents ${ }^{15,25,38-41}$ reported in literature are given in Table 2 .

The kinetics of the $\mathrm{Cr}(\mathrm{vI})$ adsorption was assessed for varying contact time period ranging from $5 \mathrm{~min}$ to $180 \mathrm{~min}$. An adsorption efficacy of $60 \%$ was achieved during initial five minutes and later the adsorption rate continued to raise steadily and attained equilibrium at $180 \mathrm{~min}$. The adsorption kinetics were evaluated using the pseudo first $\operatorname{order}^{42}$ and second order kinetics ${ }^{43}$ equations as shown below

$$
\begin{gathered}
\log \left(q_{\mathrm{e}}-q_{\mathrm{t}}\right)=\log q_{\mathrm{e}}-\frac{k_{1} t}{2.303} \\
\frac{t}{q_{\mathrm{t}}}=\frac{1}{k_{2} q_{\mathrm{e}}^{2}}+\frac{t}{q_{\mathrm{t}}}
\end{gathered}
$$

A working solution of $10 \mathrm{mg} \mathrm{L^{-1 }} \mathrm{Cr}$ (vI) was used for the kinetic studies. The data obtained from the kinetic plots (Fig. 6e and f) are tabulated in Table 3. The system followed pseudo second order kinetics with observed and calculated $q_{\mathrm{e}}$ values as 1.0446 and $1.020 \mathrm{mg} \mathrm{g}^{-1}$. The $\mathrm{Cr}(\mathrm{vI})$ uptake is majorly driven by the mechanisms such as film, particle diffusion and surface adsorption. At high $\mathrm{Cr}(\mathrm{vI})$ concentrations, intraparticle diffusion plays a major role whereas at low metal concentrations pore diffusion takes place. ${ }^{14}$ The boundary layer mechanism for efficient metal uptake is well explained by Weber-Morris intra particle diffusion model and was obtained by plotting $q_{\mathrm{t}}$ and $\sqrt{ } t$ (Fig. 6g) and ascertained through the non-zero intercept.

Table 1 Langmuir, Freundlich, Temkin and D-R isotherm parameters

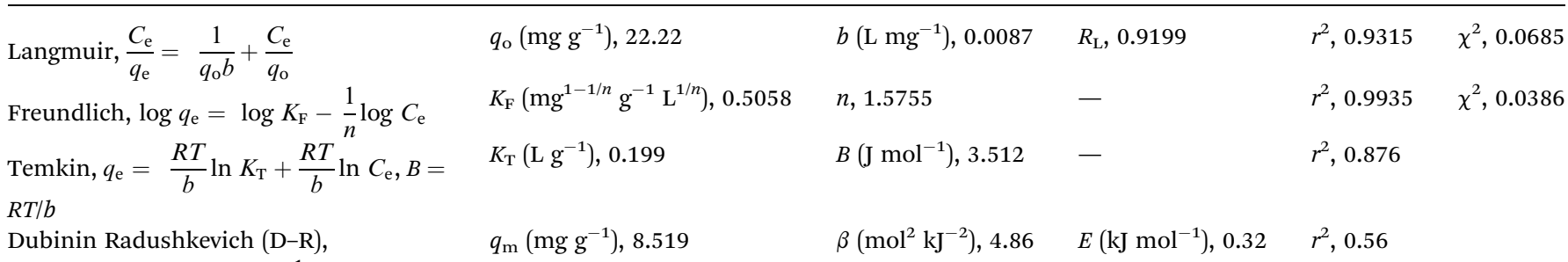

$\ln q_{\mathrm{e}}=\ln q_{\mathrm{m}}-\beta \varepsilon, E=\frac{1}{\sqrt{-2 \beta}}$ 

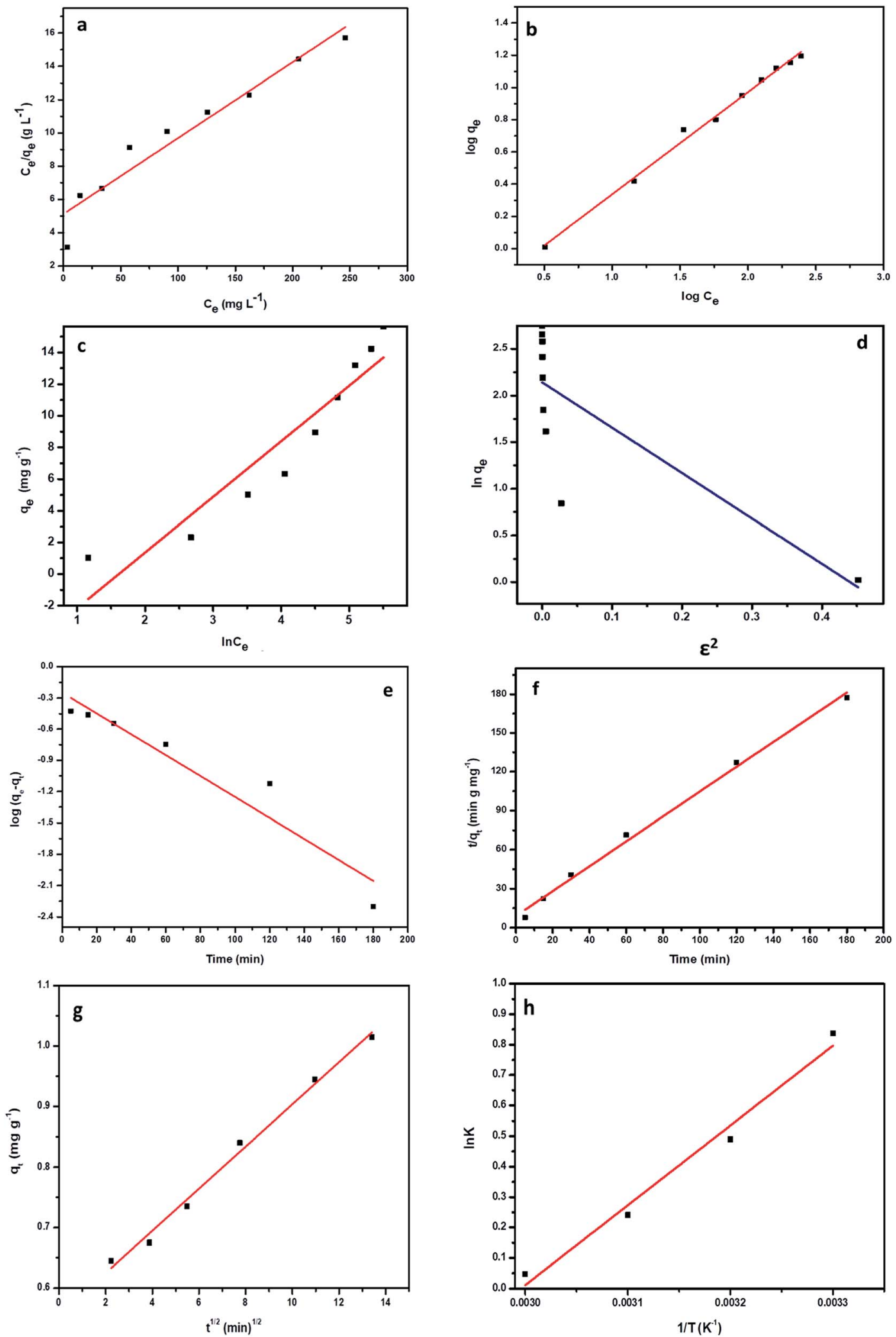

Fig. 6 (a) Langmuir isotherm (b) Freundlich isotherm (c) Temkin isotherm (d) D-R isotherm (e) plot of pseudo first order kinetics (f) plot of pseudo second order kinetics (g) intra particle diffusion (h) Van't Hoff plot.

The changes in the thermodynamic parameters such as enthalpy $(\Delta H)$, Gibbs free energy $(\Delta G)$, and entropy $(\Delta S)$ at various temperatures signifies the feasibility and nature of the adsorption reaction. The transfer of chromium from solution phase occurs onto the immobilized bacterial cell surface wherein montmorillonite acts as the primary host and the clay- 
Table 2 Comparison of biosorption capacities against few related adsorbents

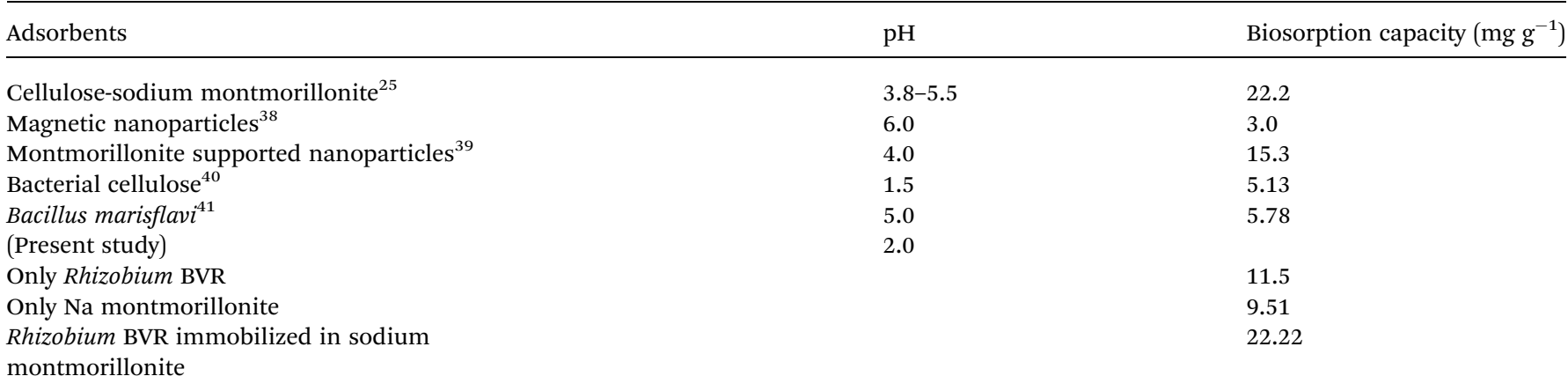

Table 3 Kinetic parameters associated with biosorption

\begin{tabular}{lllllll}
\hline$C_{\mathrm{o}}\left(\mathrm{mg} \mathrm{L}^{-1}\right)$ & $q_{\mathrm{e}}\left(\mathrm{mg} \mathrm{g}^{-1}\right)$ & $k_{2}\left(\mathrm{~g} \mathrm{mg}^{-1} \mathrm{~min}^{-1}\right)$ & $R^{2}$ & $k_{1}\left(\mathrm{~min}^{-1}\right)$ & $R_{1}{ }^{2}$ & $k_{\text {int }}\left(\mathrm{mg} \mathrm{g}^{-1} \mathrm{~min}^{-0.5)}\right.$ \\
\hline 10 & 1.0446 & 0.0584 & 0.9943 & 0.0231 & 0.9031 & 0.034
\end{tabular}

bacteria biosorbent acts as a secondary host for $\mathrm{Cr}(\mathrm{vI})$. The overall reaction Gibb's free energy change $\left(\Delta G_{\mathrm{r}}\right)$ can be explained as a summation from clay-Rhizobium surface and clay-Rhizobium-chromium surface.

$$
\Delta G_{\mathrm{r}}=\Delta G_{\text {clay-Rhizobium surface }}+\Delta G_{\text {clay-Rhizobium-Cr }}
$$

The reaction Gibb's free energy can also be correlated to the enthalpy and entropy changes as

$$
\Delta G_{\mathrm{r}}=\Delta H_{\text {clay-Rhizobium }-\mathrm{Cr}}-T \Delta S_{\text {clay-Rhizobium }-\mathrm{Cr}}
$$

At equilibrium,

$$
\begin{gathered}
\text { Clay-Rhizobium-Cr} \mathrm{r}_{\text {(solution) }} \rightleftharpoons \text { clay-Rhizobium- } \mathrm{Cr}_{(\text {surface })} \\
\Delta G_{\mathrm{r}}=\Delta G_{\mathrm{r}}^{0}+R T \ln \frac{a_{[\text {clay-Rhizobium-Cr}]_{\text {surface }}}}{a_{[\text {clay-Rhizobium-Cr }]_{\text {solution }}}}
\end{gathered}
$$

The chemical potential $\mu_{\mathrm{Cr}}=\mu_{\mathrm{Cr}}^{0}+R T \ln a_{\mathrm{Cr}}$ (solution)

In dilute solutions at ppm levels, it is reasonable to approximate the activity, $a=c$.

Table 4 Thermodynamic parameters involved in the biosorption

\begin{tabular}{llll}
$\begin{array}{l}\text { Temperature } \\
\text { Kelvin) }\end{array}$ & $\Delta G^{\circ}\left(\mathrm{kJ} \mathrm{mol}^{-1}\right)$ & $\Delta S^{\circ}\left(\mathrm{J} \mathrm{mol}^{-1} \mathrm{~K}^{-1}\right)$ & $\Delta H^{\circ}\left(\mathrm{kJ} \mathrm{mol}^{-1}\right)$ \\
\hline 303 & -2.11 & -65.202 & -21.765 \\
313 & -1.273 & & \\
323 & -0.646 & & \\
333 & -0.132 & &
\end{tabular}

Therefore,

$$
\Delta G_{\mathrm{r}}=\Delta G_{\mathrm{r}}^{0}+R T \ln \frac{[\text { clay-Rhizobium }-\mathrm{Cr}]_{\text {surface }}}{[\text { clay-Rhizobium }-\mathrm{Cr}]_{\text {solution }}}
$$

Hence,

$$
\Delta G_{\mathrm{r}}=\Delta G_{\mathrm{r}}^{0}+R T \ln K_{\mathrm{c}}
$$

At equilibrium $\Delta G_{\mathrm{r}}=0$.

$$
\Delta G_{\mathrm{r}}^{0}=-R T \ln K_{\mathrm{eq}}
$$

From the plot of $\ln K$ against $1 / T$ (Fig. 6h) the thermodynamic parameters namely, enthalpy and entropy changes were obtained from slope and intercept (Table 4). The biosorption process was spontaneous as observed from negative free energy values. Further, from the negative values of enthalpy, it is obvious that adsorption reaction is exothermic. The range of $\Delta H$ (20-40 $\mathrm{kJ} \mathrm{mol}^{-1}$ ) also indicates physico-chemical adsorption phenomenon. ${ }^{15}$ The negative $\Delta S$ value is attributed to the decreased randomness at the clay-Rhizobium-aqueous interface.

\subsection{Column studies}

3.4.1. Effect of sample volume. A higher volume of metal ion solution was tested with the developed biosorbent by performing small scale column studies. A $2.0 \mathrm{~g}$ of biosorbent was packed in a glass column of $30 \mathrm{~cm}$ length and $2 \mathrm{~cm}$ width up to a bed height of $3 \mathrm{~cm}$ (Fig. 7a). A $50 \mathrm{~mL}$ volume of $5 \mathrm{mg} \mathrm{L}^{-1} \mathrm{Cr}(\mathrm{vI})$ was passed through the column continuously and assessed periodically (10 $\mathrm{mL}$ portions) for the presence of $\mathrm{Cr}(\mathrm{vI})$ using UV- 

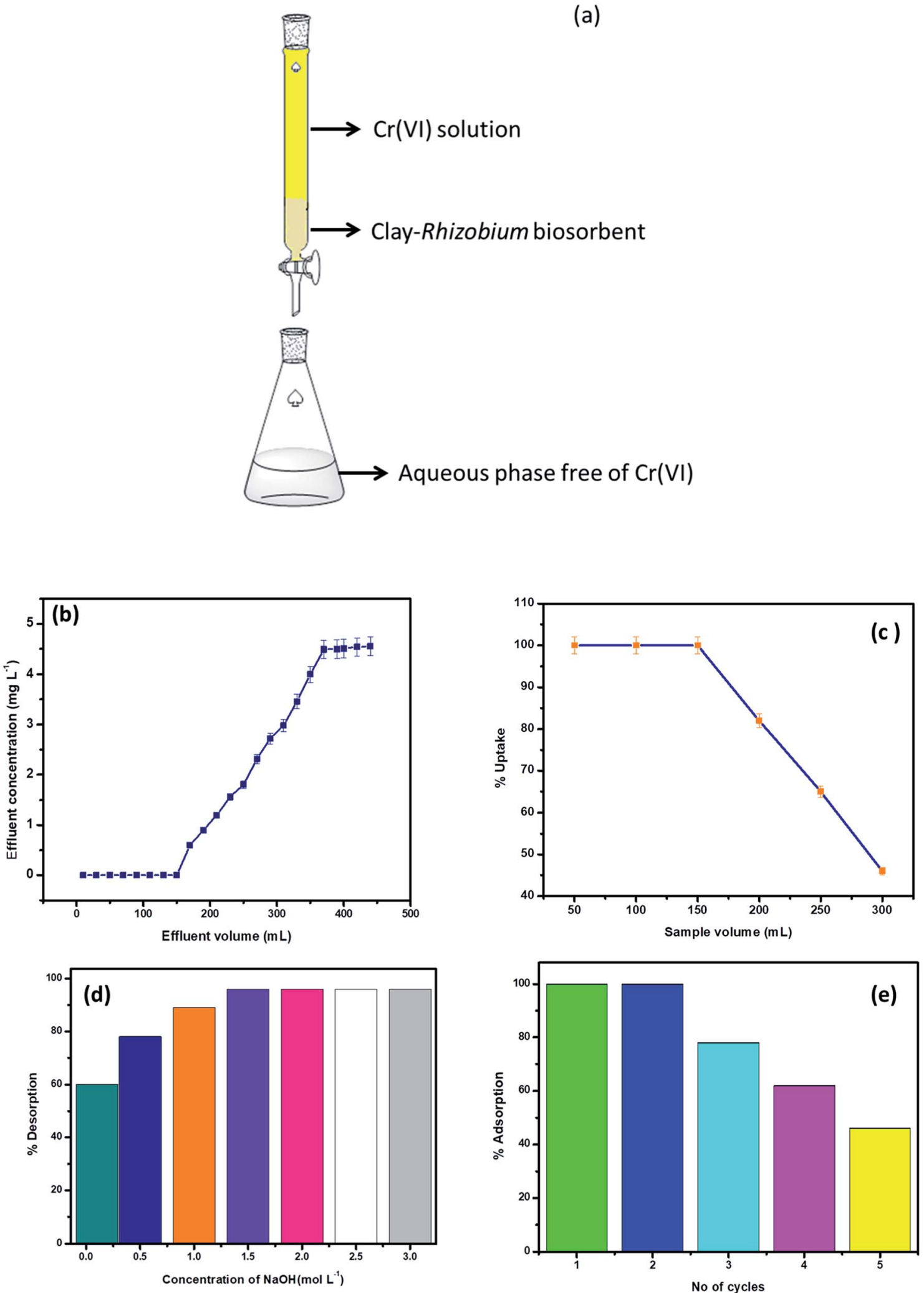

Fig. 7 (a) Diagrammatic representation of column setup for $\mathrm{Cr}(\mathrm{vI})$ treatment (b) breakthrough curve (c) effect of sample volume (d) effect of varied $\mathrm{NaOH}$ concentrations (e) regeneration efficiency of the biosorbent.

visible spectrophotometry with diphenyl carbazide as the complexing agent. ${ }^{16} \mathrm{~A}$ sample volume of $150 \mathrm{~mL}$ could be treated quantitatively beyond which the saturation of active adsorption sites decreased the metal ion adsorption (Fig. 7b and c). At higher volumes, the swelling of clay results in expansion of the bed and reduces the adsorption efficiency. 
3.4.2. Regeneration of the clay-Rhizobium biosorbent and application studies. The reusability of clay-Rhizobium biosorbent was tested using desorbing agents that were selected carefully not to inflict any damage to the biosorbent surface. The $\mathrm{Cr}(\mathrm{vI})$ adsorbed onto the biosorbent surface was eluted as sodium chromate using $10 \mathrm{~mL}$ of $1.5 \mathrm{~mol} \mathrm{~L}^{-1} \mathrm{NaOH}^{15,44}$ (Fig. 7d). Quantitative adsorption of chromium was achieved in the first two cycles and in the third cycle the adsorption was $78 \%$, followed by $62 \%$ and $46 \%$ in the fourth and fifth cycles respectively (Fig. 7e). Repeated adsorption-desorption cycles under alkaline conditions would deprotonate the biosorbent surface resulting in reduction of active sites of the biosorbent surface. The eluted $\mathrm{Cr}(\mathrm{VI})$ was converted to $\mathrm{Cr}$ (III) (less toxic) and diluted to ppb levels to minimize direct disposal of higher levels of hexavalent chromium.

The effect of diverse ionic constituents were studied independently as well as in a mixture in the concentration range as reported earlier. ${ }^{\mathbf{1 5 , 1 7}}$ Accordingly, the interference studies were performed by preparing a synthetic mixture containing ions such as $\mathrm{Cu}^{2+}, \mathrm{Pb}^{2+}, \mathrm{Co}^{2+}, \mathrm{Ni}^{2+}, \mathrm{Fe}^{2}$, nitrate, chloride and sulphate at $100 \mathrm{mg} \mathrm{L}^{-1}$ level using $5 \mathrm{mg} \mathrm{L}^{-1} \mathrm{Cr}(\mathrm{vI})$ solution. Due to the interference of sulphate and $\mathrm{Fe}^{2+}$, reduction in $\mathrm{Cr}(\mathrm{vI})$ adsorption was observed and the formation of stable metal chloro complexes $\left[\mathrm{CoCl}_{4}{ }^{2-}, \mathrm{NiCl}_{4}{ }^{2-}\right]$ also compete with hydrochromate ions thereby lowering the percentage adsorption of hexavalent chromium from aqueous phase. ${ }^{15}$

\section{Conclusions}

The developed clay-Rhizobium biosorbent showed good efficacy in adsorbing $\mathrm{Cr}(\mathrm{vI})$ from liquid phase. The adsorption followed pseudo second order kinetics and equilibrium is attained in $180 \mathrm{~min}$ with a Langmuir adsorption capacity of $22.22 \mathrm{mg} \mathrm{g}^{-1}$. Protonated surface functional groups on the Rhizobium cell surface and montmorillonite promotes effective interaction with the hydrochromate ions from liquid phase. The thermodynamics of adsorption was observed to be less random, exothermic, and spontaneous with negative entropy $\left(\Delta S^{\circ}=\right.$ $\left.-65.202 \mathrm{~J} \mathrm{~mol}^{-1} \mathrm{~K}^{-1}\right)$, enthalpy $\left(\Delta H^{\circ}=-21.765 \mathrm{~kJ} \mathrm{~mol}^{-1}\right)$ and free energy changes. The presence of $\mathrm{Cr}(\mathrm{VI})$ and trace $\mathrm{Cr}(\mathrm{III})$ were confirmed by XPS and confocal microscopy. The regeneration of biosorbent using $\mathrm{NaOH}$ was effective up to two cycles from a sample volume of $150 \mathrm{~mL}$ was also validated in a synthetic mixture of diverse ions at $100 \mathrm{mg} \mathrm{L}^{-1}$ concentration.

\section{Conflicts of interest}

The authors declare no competing interests.

\section{Acknowledgements}

We acknowledge the funding agency Department of Science and Technology (DST), India (Project No: SR/S1/IC-06-2012) for financial support and also Central Analytical Laboratory-BITS Pilani Hyderabad campus, ARCI-Hyderabad, Sprint Testing solutions-Mumbai and Surface characterization lab - IIT
Kanpur, India, for their assistance in characterization of the biosorbent.

\section{References}

1 K. Choi, S. Lee, J. O. Park, J. A. Park, S. H. Cho, S. Y. Lee, J. H. Lee and J. W. Choi, Chromium removal from aqueous solution by a PEI-silica nanocomposite, Sci. Rep., 2018, 8, 1438.

2 J. F. Gutierrez-Corona, P. Romo-Rodríguez, F. SantosEscobar, A. E. Espino-Saldana and H. Hernández-Escoto, Microbial interactions with chromium: basic biological processes and applications in environmental biotechnology, World J. Microbiol. Biotechnol., 2016, 32, 191.

3 A. S. K. Kumar, S. J. Jiang and W. L. Tseng, Effective adsorption of chromium(vi)/Cr(III) from aqueous solution using ionic liquid functionalized multiwalled carbon nanotubes as a super sorbent, J. Mater. Chem. A, 2015, 3, 7044-7057.

4 USEPA, Analytical feasibility document for the six year review of existing national primary drinking water regulation, office of ground water and drinking water EPA $815 R$ 03, EPA, Washington DC, 2003.

5 B. Dhal, H. N. Thatoi, N. N. Das and B. D. Pandey, Chemical and microbial remediation of hexavalent chromium from contaminated soil and mining/metallurgical solid waste: a review, J. Hazard. Mater., 2013, 250-251, 272-291.

6 M. Fomina and G. M. Gadd, Biosorption: current perspectives on concept, definition and application, Bioresour. Technol., 2014, 160, 3-14.

7 J. R. Dodson, H. L. Parker, A. M. García, A. Hicken, K. Asemave, T. J. Farmer, H. V. He, J. H. Clark and A. J. Hunt, Bio-derived materials as a green route for precious \& critical metal recovery and re-use, Green Chem., 2015, 17, 1951-1965.

$8 \mathrm{M}$. Shanmugaprakash and V. Sivakumar, Competitive biosorption of $\mathrm{Cr}(\mathrm{VI})$ and $\mathrm{Zn}$ (II) ions in single and binarymetal systems onto a biodiesel waste residue using batch and fixed-bed column studies, RSC Adv., 2015, 5, 4581745826.

9 V. Javanbakht, S. A. Alavi and H. Zilouei, Mechanisms of heavy metal removal using microorganisms as biosorbent, Water Sci. Technol., 2014, 69, 1775-1787.

10 A. Ostovan, M. Ghaedi, M. Arabi, Q. Yang, J. Li and L. Chen, Hydrophilic Multi-template Molecularly Imprinted Biopolymers Based on a Green Synthesis Strategy for Determination of B-family Vitamins, ACS Appl. Mater. Interfaces, 2018, 10, 4140-4150.

11 A. Ostovan, M. Ghaedi and M. Arabi, Fabrication of watercompatible superparamagnetic molecularly imprinted biopolymer for clean separation of baclofen from bio-fluid samples: a mild and green approach, Talanta, 2018, 179, 760-768.

12 M. Arabi, A. Ostovan, M. Ghaedi and M. K. Purkait, Novel strategy for synthesis of magnetic dummy molecularly imprinted nanoparticles based on functionalized silica as an efficient sorbent for the determination of acrylamide in 
potato chips: optimization by experimental design methodology, Talanta, 2016, 154, 526-532.

13 M. Arabi, M. Ghaedi and A. Ostovan, Development of a Lower Toxic Approach Based on Green Synthesis of Water-Compatible Molecularly Imprinted Nanoparticles for the Extraction of Hydrochlorothiazide from Human Urine, ACS Sustainable Chem. Eng., 2017, 5, 3775-3785.

14 T. Sathvika, Manasi, V. Rajesh and N. Rajesh, Microwave assisted immobilization of yeast in cellulose biopolymer as a green adsorbent for the sequestration of chromium, Chem. Eng. J., 2015, 279, 38-46.

15 T. Sathvika, A. Soni, K. Sharma, M. Praneeth, M. Manasi, V. Rajesh and N. Rajesh, Potential application of Saccharomyces cerevisiae and Rhizobium immobilized in multiwalled carbon nanotubes to adsorb hexavalent chromium, Sci. Rep., 2018, 8, 9862.

16 T. Sathvika, Manasi, V. Rajesh and N. Rajesh, Prospective application of Aspergillus species immobilized in sodium montmorillonite to remove toxic hexavalent chromium from wastewater, RSC Adv., 2015, 5, 107031-107044.

17 T. Sathvika, M. Manasi, V. Rajesh and N. Rajesh, Leveraging the Potential of Endomycorrhizal Spores and Montmorillonite for Hexavalent Chromium Adsorption from Aqueous Phase, ChemistrySelect, 2018, 3, 2747-2755.

18 D. Park, Y. S. Yun, J. H. Jo and J. M. Park, Mechanism of hexavalent chromium removal by dead fungal biomass of Aspergillus niger, Water Res., 2005, 39, 533-540.

19 S. Sivakumaran, P. Lockhart and B. D. Jarvis, Identification of soil bacteria expressing a symbiotic plasmid from Rhizobium leguminosarum bv. Trofolii., Can. J. Microbiol., 1997, 43, 164-177.

20 S. Ehteshamul-haque and A. Ghaffar, Use of Rhizobia in the Control of Root Rot Diseases of Sunflower, Okra, Soybean and Mungbean, J. Phytopathol., 1993, 138, 157-163.

21 F. B. Rebah, D. Prévost, A. Yezza and R. D. Tyagi, Agroindustrial waste materials and wastewater sludge for rhizobial inoculant production: a review, Bioresour. Technol., 2007, 98, 3535-3546.

22 N. Raaman, B. Mahendran, C. Jaganathan, S. Sukumar and V. Chandrasekaran, Removal of chromium using Rhizobium leguminosarum, World J. Microbiol. Biotechnol., 2012, 28, 627-636.

23 N. García-Gonzalez, B. A. Frontana-Uribe, E. Ordonez-Regil, J. Cardenas and J. A. Morales-Serna, Evaluation of $\mathrm{Fe}^{3+}$ fixation into montmorillonite clay and its application in the polymerization of ethylenedioxythiophene, RSC Adv., 2016, 6, 95879.

24 B. S. Kumar, A. Dhakshinamoorthy and K. Pitchumani, K10 Montmorillonite clays as environmentally benign catalysts for organic reactions, Catal. Sci. Technol., 2014, 4, 23782396.

25 A. S. K. Kumar, S. Kalidhasan, V. Rajesh and N. Rajesh, Application of cellulose-clay composite biosorbent toward the effective adsorption and removal of chromium from industrial wastewater, Ind. Eng. Chem. Res., 2012, 51, 58-69.

26 R. W. Raylor, J. S. Shen, W. F. Bleam and S.-i tu, Chromate removal by dithionite-reduced clays: evidence from direct
X-ray adsorption near edge spectroscopy (XANES) of chromate reduction at clay surfaces, Clays Clay Miner., 2000, 48, 648-654.

$27 \mathrm{H}$. Dong, Clay-Microbe Interactions and implications for environmental mitigation, Elements, 2012, 8, 113-118.

$28 \mathrm{M}$. Boufait and H. A. Amar, Removal of $N, N$-dimethylaniline from a dilute aqueous solution by $\mathrm{Na}^{+} / \mathrm{K}^{+}$saturated montmorillonite, Desalination, 2007, 206, 300-310.

29 Y. Xiang, L. Mei, N. Li and A. Tong, Sensitive and selective spectrofluorimetric determination of chromium(VI) in water by fluorescence enhancement, Anal. Chim. Acta., 2007, 581, 132-136.

30 Y. Zhou, J. Zhang, L. Zhang, Q. Zhang, T. Ma and J. Niu, A rhodamine-based fluorescent enhancement chemosensor for the detection of $\mathrm{Cr}^{3+}$ in aqueous media, Dyes Pigm., 2013, 97, 148-154.

31 E. J. Arar and J. D. Pfaff, Determination of dissolved hexavalent chromium in industrial wastewater effluents by ion chromatography and post-column derivatization with diphenylcarbazide, J. Chromatogr. A, 1991, 546, 335-340.

32 D. Naumann, Infra-red spectroscopy in microbiology, Encyclopaedia of Analytical Chemistry, ed. R. A. Meyers, John Wiley and Sons Ltd., Chichester, 2000, pp. 102-131.

33 Y. Mu, Z. Ai, L. Zhang and F. Song, Insight into core-shell dependent anoxic $\mathrm{Cr}(\mathrm{VI})$ removal with $\mathrm{Fe}_{2} \mathrm{Fe}_{2} \mathrm{O}_{3}$ nanowires: indispensable role of surface bound $\mathrm{Fe}(\mathrm{II}), A C S$ Appl. Mater. Interfaces, 2015, 7, 1997-2005.

34 J. D. Ramsey and R. L. McCreery, In situ Raman microscopy of chromate effects on corrosion pits in aluminum alloy, $J$. Electrochem. Soc., 1999, 146, 4076-4081.

35 M. Ghanimati, M. Jabbari, A. Farajtabar and S. A. NabaviAmri, Adsorption kinetics and isotherms of bioactive antioxidant quercetin onto amino-functionalized silica nanoparticles in aqueous ethanol solutions, New J. Chem., 2017, 41, 8451.

36 Y. Chen, B. Wang, J. Xin, P. Sun and D. Wu, Adsorption behavior and mechanism of $\mathrm{Cr}(\mathrm{VI})$ by modified biochar derived from Enteromorpha prolifera, Ecotoxicol. Environ. Saf., 2018, 164, 440-447.

37 C. Sun, L. Sun and X. Sun, Graphical evaluation of the favorability of adsorption processes by using conditional Langmuir constant, Ind. Eng. Chem. Res., 2013, 52, 1425114260.

38 Y. C. Sharma and V. Srivastava, Comparative studies of removal of $\mathrm{Cr}(\mathrm{VI})$ and $\mathrm{Ni}(\mathrm{II})$ from aqueous solutions by magnetic nanoparticles, J. Chem. Eng. Data, 2011, 56, 819825.

39 P. Yuan, M. Fan, D. Yang, H. He, D. Liu, A. Yuan, J. Zhu and T. Chen, Montmorillonite-supported magnetite nanoparticles for the removal of hexavalent chromium [Cr(VI)] from aqueous solutions, J. Hazard. Mater., 2009, 166, 821-829.

40 M. Lu, Y. Xu, X. Guan and D. Wei, Preliminary research on $\mathrm{Cr}(\mathrm{VI})$ removal by bacterial cellulose, J. Wuhan Univ. Technol., Mater. Sci. Ed., 2012, 27, 572-575.

$41 \mathrm{~S}$. Mishra and M. Doble, Novel chromium tolerant microorganisms: isolation, characterization and their 
biosorption capacity, Ecotoxicol. Environ. Saf., 2008, 71, 874879.

42 A. K. Mishra, V. K. Shahi, N. R. Agrawal and I. Das, Synthesis, characterization, and application of a thiophene-pyrrole copolymer as an efficient adsorbent for removal of methylene blue, J. Chem. Eng. Data, 2018, 63, 3206-3214.
43 Y. S. Ho and G. Mckay, The kinetics of sorption of divalent metal ions onto sphagnum moss peat, Water Res., 2000, 34, 735-742.

44 T. Sathvika, S. Balaji, M. Chandra, A. Soni, V. Rajesh and N. Rajesh, A co-operative endeavor by nitrifying bacteria Nitrosomonas and zirconium based metal organic framework to remove hexavalent chromium, Chem. Eng. J., 2019, 360, 879-889. 